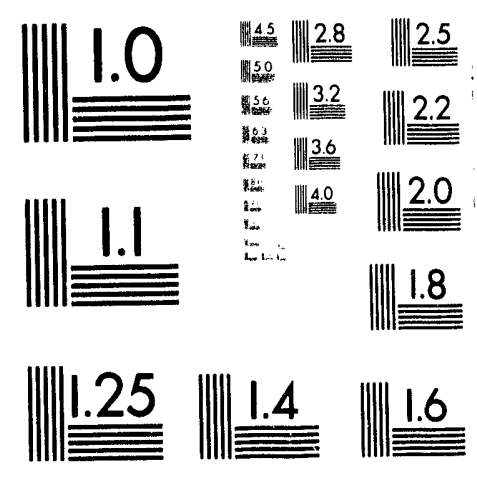



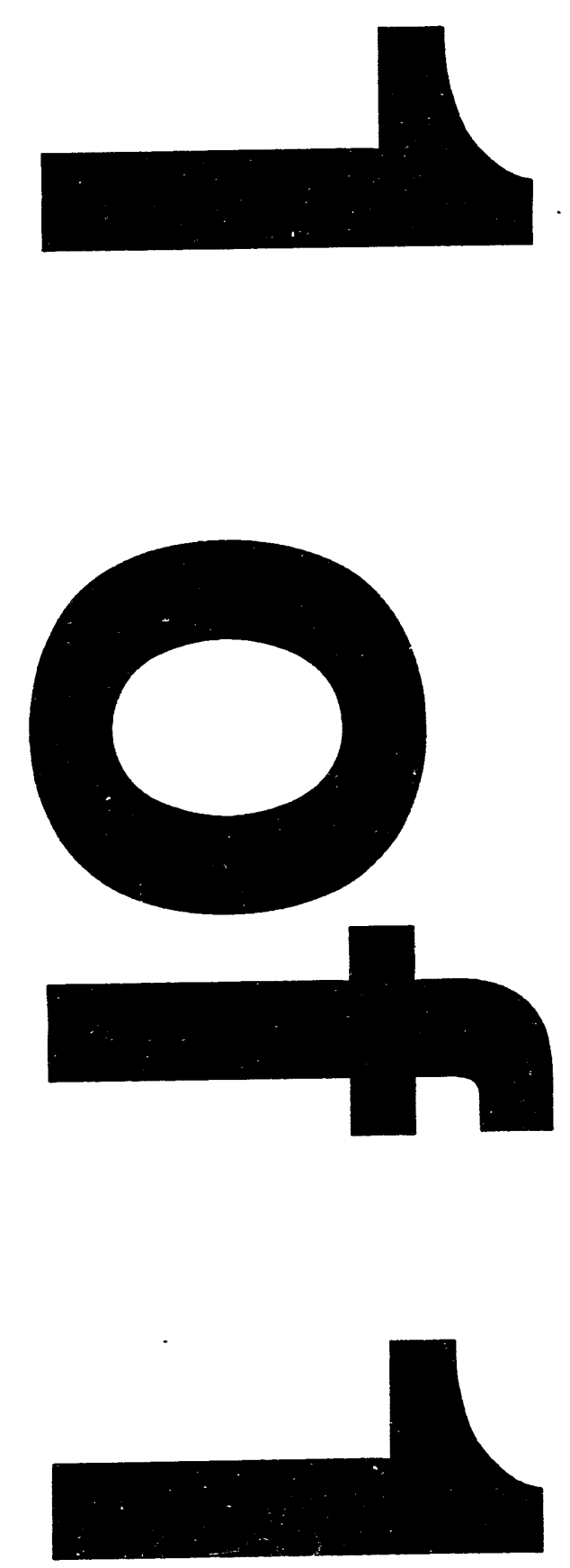
ORNL/CON-318

\title{
EVALUATION OF POTENTIAL PERFORMANCE ADDITIVES FOR THE ADVANCED LITHIUM BROMIDE CHILLER
}

\author{
R. H. Reiner \\ W. Del Cul \\ H. Perez-Blanco \\ M. R. Ally \\ A. Zaltash
}

April 1991

Thermally Activated Heat Pump Research DOE/ORNL Building Equipment Research Program

Oak Ridge National Laboratory

Prepared by the

OAK RIDGE NATIONAL LABORATORY

managed by

MARTIN MARIETTA ENERGY SYSTEMS, INC.

Oak Ridge, Tennessee 37831-6285 for the

U. S. DEPARTMENT OF ENERGY under Contract No. DE-AC05-84OR21400 


\section{TABLE OF CONTENTS}

LIST OF FIGURES $\ldots \ldots \ldots \ldots \ldots \ldots \ldots \ldots \ldots \ldots \ldots \ldots \ldots$

LIST OF TABLES $\ldots \ldots \ldots \ldots \ldots \ldots \ldots \ldots \ldots \ldots \ldots \ldots$ vii

ACKNOWLEDGMENTS $\ldots \ldots \ldots \ldots \ldots \ldots \ldots \ldots \ldots \ldots \ldots \ldots$ ix

ABSTRACT $\ldots \ldots \ldots \ldots \ldots \ldots \ldots \ldots \ldots \ldots \ldots \ldots \ldots \ldots \ldots \ldots$

NOMENCLATURE $\ldots \ldots \ldots \ldots \ldots \ldots \ldots \ldots \ldots \ldots \ldots \ldots \ldots \ldots$ xii

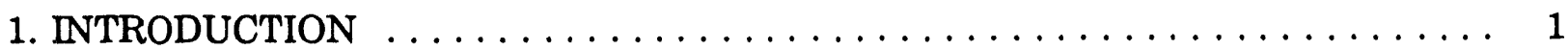

2. EXPERIMENTAL PROCEDURE AND DESCRIPTION $\ldots \ldots \ldots \ldots \ldots \ldots \ldots$

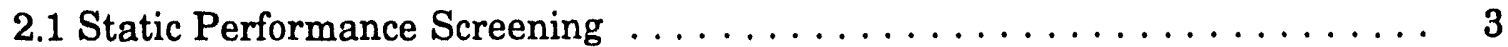

2.2 Dynamic Performance Testing . . . . . . . . . . . . . . . . 3

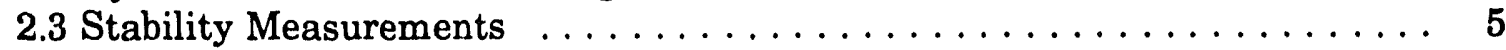

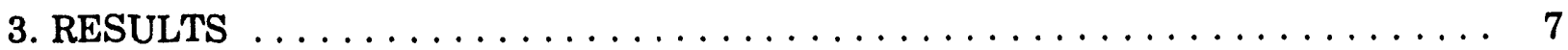

3.1 Static Performance Enhancement Results $\ldots \ldots \ldots \ldots \ldots \ldots \ldots \ldots \ldots$

3.2 Dynamic Performance Enhancement Results . . . . . . . . . . . . 12

3.3 Thermal and Chemical Stability Results . . . . . . . . . . . . . . 14

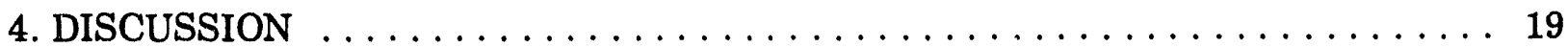

4.1 Static Performance Enhancement . . . . . . . . . . . . . . . . . . 19

4.2 Dynamic Performance Enhancement . . . . . . . . . . . . . . 19

4.3 Thermal and Chemical Stability . . . . . . . . . . . . . . . . 20

4.4 Implications for Advanced Chiller Development $\ldots \ldots \ldots \ldots \ldots \ldots \ldots$

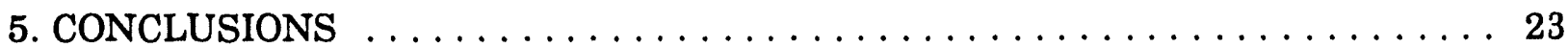

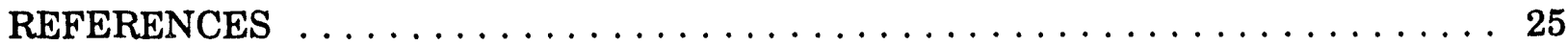




\section{LIST OF FIGURES}

Fig. 1. Schematic of minisorber apparatus used to evaluate performance additive effectiveness.

Fig. 2. Performance (mass transfer) enhancement, E, as a function of 2-ethyl-1hexanol concentration, $[2 \mathrm{EH}]$, in a static pool of aqueous $\mathrm{LiBr} \ldots \ldots \ldots \ldots$

Fig. 3. Performance (heat transfer) enhancement, $E_{H}$, as a function of 2-ethyl-1hexanol concentration, $[2 \mathrm{EH}]$, in a falling film absorber. . . . . . . . . 13

Fig. 4. Thermal stability of $2 \mathrm{EH}$ (2-ethyl-1-hexanol) obtained by DSC (differential

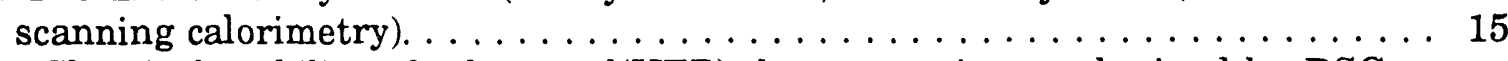

Fig. 5. Chemical stability of 1 -heptanol(HEP)-chromate mixture obtained by DSC (differential scanning calorimetry). 


\section{LIST OF TABLES}

Table 1. Performance (mass transfer) enhancement, E, as a function of 2-ethyl-1hexanol concentration, [2EH]

Table 2. Static performance enhancement, E, as a function of 1-heptanol concentration, [HEP]

Table 3. Static performance enhancement, E, as a function of $1 \mathrm{H}, 1 \mathrm{H}, 7 \mathrm{H}$-dodecafluoro-

1-heptanol concentration, [DFH]
4. Static performance enhancement

Table 4. Static performance enhancement, E, as a function of 1,1,1-trifluoro-2-octanol

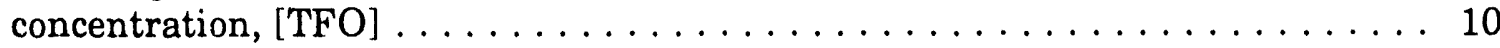

Table 5. Maximum static enhancement, $\mathrm{E}_{\mathrm{M}}$ of various additives . . . . . . . . 11

Table 6. Comparison of performance enhancement, $\mathrm{E}_{\mathrm{M}}$, with mechanical stirring and

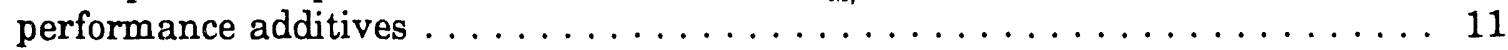

Table 7. Effect of additive combination on performance enhancement $\ldots \ldots \ldots \ldots 12$

Table 8. Minisorber performance enhancement of various additives . . . . . . . . . . 14

Table 9. Stability of performance additives in various environments $\ldots \ldots \ldots \ldots 16$ 


\section{ACKNOWLEDGMENTS}

The authors wish to thank D. E. Holt for helping operate the static pool apparatus and John Cole for operating (and repairing) the DSC. We also thank R. C. DeVault for reviewing and discussing this manuscript. 


\begin{abstract}
The effectiveness and stability of potential heat-and-mass transfer (performance) additives for an advanced lithium bromide ( $\mathrm{LiBr}$ ) chiller were evaluated in a series of experimental studies. These studies of additive effectiveness and stability were necessary because many currently used performance additives decompose at the high generator temperatures $\left(220^{\circ} \mathrm{C}\right.$ to $\left.260^{\circ} \mathrm{C}\right)$ desired for this particular advanced $\mathrm{LiBr}$ chiller. For example, one common performance additive, 2-ethyl-1-hexanol $(2 \mathrm{EH})$, reacts with the corrosion inhibitor, lithium chromate $\left(\mathrm{Li}_{2} \mathrm{CrO}_{4}\right)$, even at moderate generator temperatures $\left(\geq 180^{\circ} \mathrm{C}\right)$.

These stability problems can be mitigated by using less reactive corrosion inhibitors such as lithium molybdate $\left(\mathrm{Li}_{2} \mathrm{MoO}_{4}\right)$ and by using more stable performance additives such as 1 heptanol (HEP) or $1 \mathrm{H}, 1 \mathrm{H}, 7 \mathrm{H}$-dodecafluc: 0 -1-heptanol $(\mathrm{DFH})$. There seems to be a trade-off between additive stability and effectiveness: the most effective performance additives are not the most stable additives. These studies indicate that HEP or DFH may be effective additives in the advanced $\mathrm{LiBr}$ chiller if $\mathrm{Li}_{2} \mathrm{MoO}_{4}$ is used as a corrosion inhibitor.
\end{abstract}




\section{NOMENCLATURE}

This section includes a summary and brief description of the symbols used in this report. More detailed descriptions are provided at the appropriate locations in the text.

Symboi $\quad \underline{\text { Definition/Description }}$

E Mass Transfer Enhancement. Mass ratio of water vapor absorbed with additive to water vapor absorbed without additive in static pool experiments.

$\mathrm{E}_{\mathrm{M}} \quad$ Maximum Mass Transfer Enhancement. Maximum value of $\mathrm{E}$ for a particular performance additive in static pool experiments.

$\mathrm{E}_{\mathrm{H}} \quad$ Heat Transfer Enhancement. Ratio of absorber heat transfer coefficient with additive to heat transfer coefficient without additive in minisorber experiments.

$\overline{\mathbf{E}}_{\mathrm{H}} \quad$ Average Heat Transfer Enhancement. Average value of $\mathrm{E}_{\mathrm{H}}$ at additive concentrations above the threshold necessary for maximum enhancement in the minisorber experiments.

[LiBr] Lithium Bromide ( $\mathrm{LiBr}$ ) Concentration. Concentration of $\mathrm{LiBr}$ in absorber solution in either static pool or minisorber experiments (wt \%).

$\dot{\mathbf{m}}$

Solution Mass Flow Rate. Mass flow rate of the LiBr solution entering absorber in minisorber experiments ( $\mathrm{g} / \mathrm{min}$ ).

$\mathrm{T} \quad$ LiBr Solution Temperature. LiBr solution temperature in static pool experiments $\left({ }^{\circ} \mathrm{C}\right)$.

$\mathrm{T}_{\mathrm{F}} \quad$ Average Solution Film Temperature. Average film temperature of the $\mathrm{LiBr}$ film on absorber tube in minisorber experiments $\left({ }^{\circ} \mathrm{C}\right)$.

$\mathrm{T}_{\mathrm{R}} \quad$ Additive Reaction Onset Temperature. Temperature at which additive begins to react or decompose in the differential scanning calorimeter $\left({ }^{\circ} \mathrm{C}\right)$.

$\mathrm{X} \quad$ Performance Additive, $\mathrm{X}$. Identity of the performance additive, $\mathrm{X}$, in the LiBr solutions in the static pool or minisorber experiments.

[X] Additive Concentration. Concentration of additive, $\mathrm{X}$, in the LiBr solution in either static pool or minisorber experiments (weight parts per million, wppm). 
$[\mathrm{X}]_{\mathrm{M}}$ Optimum Additive Concentration for Maximum Enhancement. Additive concentration in $\mathrm{LiBr}$ solution at which performance enhancement, $\mathrm{E}$, is a maximum in static pool experiments (wppm). 


\section{INTRODUCTION}

Conventional single- and double-effect absorption chillers operate at generator temperatures below $170^{\circ} \mathrm{C}$ with lithium bromide ( $\mathrm{LiBr}$ ) and water as the absorbent solution." They employ a performance additive such as 2-ethyl-1-hexanol (2EH) to enhance heat and mass transfer and a corrosion inhibitor such as lithium chromate $\left(\mathrm{Li}_{2} \mathrm{CrO}_{4}\right)$ to protect the chiller components. The aqueous $\mathrm{LiBr}$ solution may also be buffered with a small amount of lithium hydroxide ( $\mathrm{LiOH})$ to optimize corrosion inhibition. ${ }^{2}$

Several advanced chiller cycles have been identified that show technical and economic potential. The advanced cycles under consideration are for triple-effect class chillers that can potentially operate at $50 \%$ higher efficiency than the best currently used double-effect equipment. ${ }^{3}$ Most of the advanced cycles require component operation at temperatures significantly higher than those of present equipment.

The advanced $\mathrm{LiBr}$ chiller cycle of immediate interest requires generator temperatures between $220^{\circ}$ and $260^{\circ} \mathrm{C} .{ }^{4}$ Several issues arise because of the higher generator temperature. These technical issues were discussed in detail in a previous document. ${ }^{5}$ Briefly, these issues include (1) additive effectiveness, (2) additive thermal stability, (3) additive reactivity with corrosion inhibitors (chemical stability), and (4) corrosion resistance of generator materials. The additive effectiveness and stability issues may present major technical problems to $\mathrm{LiBr}$ chiller development because there is insufficient understanding of (1) how performance additives work, (2) the thermal stability of current additives, and (3) interactions between additives and corrosion inhibitors.

This report describes experimental studies of performance additive effectiveness and stability. Three experimental activities were undertaken to evaluate potential additives: (1) static performance screening of a large selection of candidates, (2) subsequent dynamic performance testing of a few of the best candidates, and (3) subsequent stability testing of these performance additives at conditions relevant to advanced $\mathrm{LiBr}$ chiller operation. The experimental procedures and equipment used in these studies are described in Section 2 of this report. In Section 3, results of these experimental studies are presented. The implications of these results are then discussed in Section 4 and summarized in Section 5 of this report. 


\section{EXPERIMENTAL PROCEDURE AND DESCRIPTION}

\subsection{Static Performance Screening}

A large number of performance additive candidates were screened by measuring their effects on the rate of water vapor absorption in a static pool of aqueous $\mathrm{LiBr}$. Such static pool absorption tests have previously been used by several researchers to estimate the effectiveness of performance additives. ${ }^{6,7}$ Static pool tests are cheaper and faster than dynamic tests and provide an easy method of screening performance additives. However, because static pool conditions are different than those encountered in a falling film absorber, static pool tests cannot quantitatively predict additive performance in an operating chiller.

The experimental equipment used in these studies is similar to that described by other researchers. ${ }^{7,8}$ A typical static pool measurement consisted of exposing a 50-ml sample of 60 wt \% aqueous $\mathrm{LiBr}$ at $20^{\circ} \mathrm{C}$ to a constant pressure of water vapor $(\approx 17.5$ torr $)$. The $\mathrm{LiBr}$ solution and water vapor reservoir were contained in a vacuum system to facilitate water vapor absorption at subatmospheric pressures. The surface area of $\mathrm{LiBr}$ solution exposed to water vapor was $-63 \mathrm{~cm}^{2}$.

Static screening exposures were conducted in the following manner. Prior to each exposure, the water vapor reservoir and $\mathrm{LiBr}$ solution were degassed at low pressure to remove noncondensible gases such as nitrogen or oxygen. During each exposure, the $\mathrm{LiBr}$ solution temperature slowly increased as water vapor was adiabatically absorbed for 15 minutes. After each exposure, the quantity of absorbed water vapor was determined from the change in $\mathrm{LiBr}$ concentration by measuring the refractive index of the $\mathrm{LiBr}$ solution. In a typical experiment, between 2 and $7 \mathrm{~g}$ of water vapor was absorbed by the LiBr solution during a 15-minute exposure. The relative enhancement of a specific performance additive was determined by comparing the quantity of absorbed water vapor in experiments with and without the additive. The relative enhancement was then determined as a function of additive concentration for each additive evaluated.

\subsection{Dynamic Performance Testing}

Although static pool tests are cheaper and faster than dynamic falling-film absorber tests, static pool tests cannot predict machine performance because test conditions are different. For example, brine exposure time, film thickness, film hydrodynamics, and temperature gradients are significantly different in a static pool than in a falling film absorber. ${ }^{9}$ Dynamic minisorber (or single-tube absorber) tests are necessary to quantitatively measure heat-andmass transfer enhancement because the static pool conditions are not comparable to machine absorber operation.

Several of the most promising additives evaluated in the static pool were subsequently tested in a falling film minisorber. The experimental design of this minisorber has previously been described in some detail. ${ }^{10}$ A schematic of the minisorber is shown in Figure 1. Briefly, the falling film absorber consists of a single vertical tube, $19 \mathrm{~mm}$ in diameter and approximately $1 \mathrm{~m}$ in length. Instrumentation on the minisorber was automated to continuously measure $\mathrm{LiBr}$ solution flow rates and temperatures. These temperatures and flow measurements were used to calculate absorber heat transfer coefficients. Mass transfer coefficients could not be accurately determined because of instrument limitations. 


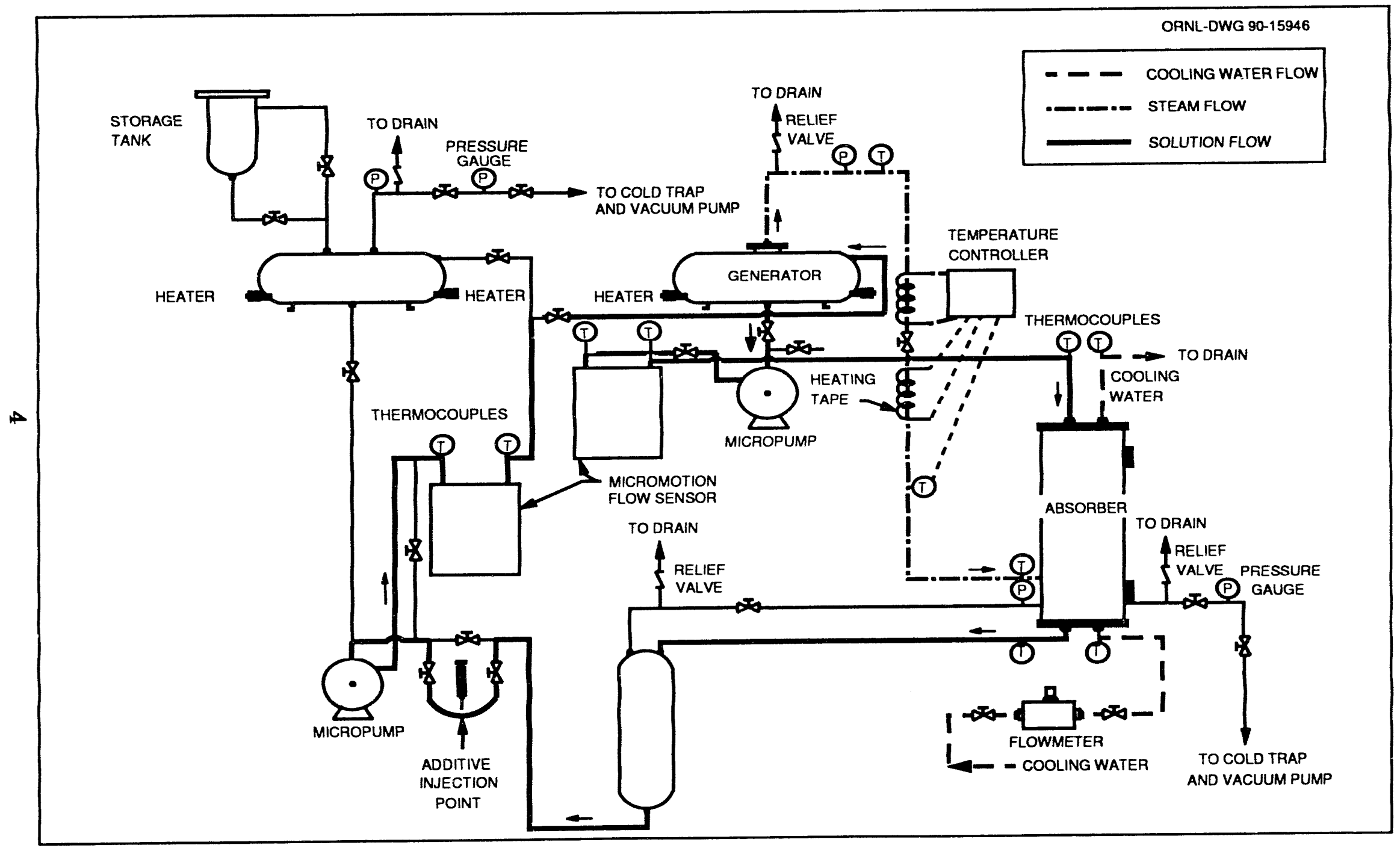

Fig. 1. Schematic of minisorber apparatus used to evaluate performance additive effectiveness. 
During a typical minisorber experiment, the solution concentration entering the absorber was $61 \mathrm{wt} \% \mathrm{LiBr}$, while the solution concentration leaving the absorber was $-57 \mathrm{wt} \% \mathrm{LiBr}$. The average solution film temperature in the absorber was maintained between $92^{\circ} \mathrm{C}$ and $96^{\circ} \mathrm{C}$. (Lower film temperatures could not be attained due to previous minisorber design constraints. ${ }^{10}$ ) Performance additive effectiveness was determined by comparing steady-state absorber heat transfer with and without an additive present. For each additive evaluated in the minisorber, effectiveness was determined at several different additive concentrations.

\subsection{Stability Measurements}

Stability testing is necessary to determine the extent of additive decomposition at high generator temperatures $\left(220^{\circ} \mathrm{C}\right.$ to $\left.260^{\circ} \mathrm{C}\right)$. Previous results indicated that at high temperatures additives can either thermally decompose ${ }^{11}$ or can react with corrosion inhibitors. ${ }^{2}$ Initially, we planned to evaluate additive stability at conditions (temperatures, concentrations, and pressures) anticipated in the high-temperature generator. However, because performance additives and corrosion inhibitors are typically present in very dilute concentration ( $-100 \mathrm{wppm}$ to $2000 \mathrm{wppm})$, it was not possible to accurately measure additive stability at these conditions. (Accurate measurements required quantitative extraction of trace amounts of additive from the $\mathrm{LiBr}$ solution. Attempts to perform this extraction were not quantitative and not reproducible. ${ }^{12}$ ) Instead, relative rates of additive decomposition and additive reaction with corrosion inhibitors were determined as functions of temperature using a differential scanning calorimeter (DSC).

The DSC measures the enthalpy changes produced by thermal decomposition or chemical reaction. When a sample in the DSC is heated at a constant rate, its temperature increases linearly with time. The DSC is purged and backfilled with argon to prevent sample reaction with ambient oxygen during heating. Sample decomposition or reaction is indicated by a change in the quantity of heat flowing into the sealed sample capsules. The temperature at which the change in heat flow occurs (onset temperature) is an indicator of relative sample stability. The higher the onset temperaiture, the more stable the sample.

The relative thermal and chemical stabilities of several additives were compared using the DSC. Thermal stability was evaluated by measuring the onset temperature for each additive. Relative thermal stability of the additives was determined by comparing onset temperatures. Chemical stability of various additives was evaluated in a similar manner. The onset temperatures of specific additive-inhibitor mixtures were measured in the DSC to determine the chemical stability of each mixture. Two currosion inhibitors commonly used in $\mathrm{LiBr}$ chillers are $\mathrm{Li}_{2} \mathrm{CrO}_{4}$ and lithium molybdate $\left(\mathrm{Li}_{2} \mathrm{MoO}_{4}\right)$. In these studies, potassium chromate $\left(\mathrm{K}_{2} \mathrm{CrO}_{4}\right)$ was substituted for $\mathrm{Li}_{2} \mathrm{CrO}_{4}$ and sodium molybdate $\left(\mathrm{Na}_{2} \mathrm{MoO}_{4}\right)$ was substituted for $\mathrm{Li}_{2} \mathrm{MoO}_{4}$ as an experiment convenience. (The substituted chemicals were readily available; the lithium compounds were not. Chemical reactivity of performance additives with the substituted inhibitors should be essentially identical to additive reactivity with the lithium inhibitors.) Comparisor of mixture onset temperatures provided a relative measure of the chemical stability of various additive-inhibitor combinations. 


\section{RESULTS}

\subsection{Static Performance Enhancement Results}

The performance enhancement of various additives was determined by comparing the mass of water vapor absorbed by $\mathrm{LiBr}$ solutions with and without additive present. To facilitate this comparison, a mass transfer enhancement, E, was defined. Enhancement, E, is the mass of water absorbed in an $\mathrm{LiBr}$ solution containing additive, divided by mass of water absorbed in a similar $\mathrm{LiBr}$ solution not containing any additive. The performance enhancement measurements, $\mathrm{E}$, for various concentrations of $2 \mathrm{EH},[2 \mathrm{EH}]$, are summarized in Table 1. These results were obtained in aqueous $\mathrm{LiBr}$ solutions where, initially, $\mathrm{T}=20^{\circ} \mathrm{C}$ and $[\mathrm{LiBr}]=60 \mathrm{wt} \%$.

Table 1. Performance (mass transfer) enhancement, E, as a function of 2-ethyl-1-hexanol concentration, $[2 \mathrm{EH}]^{a, b}$

\begin{tabular}{rl}
\hline $2 \mathrm{EH}]$ & \\
$\frac{\mathrm{E}}{(\text { wppm })}$ & \\
0 & 1.0 \\
210 & 4.9 \\
315 & 5.3 \\
415 & 6.4 \\
625 & 8.3 \\
680 & 7.5 \\
780 & 7.6 \\
990 & 3.5 \\
1380 & 1.8 \\
\hline
\end{tabular}

${ }^{\circ}$ Initial Conditions: $[\mathrm{LiBr}]=60 \mathrm{wt} \%, \mathrm{~T}=20^{\circ} \mathrm{C}$.

${ }^{b} \mathrm{E}_{\mathrm{M}}=9.0,[2 \mathrm{EH}]_{\mathrm{M}}=566 \mathrm{wppm}$.

The performance enhancements in Table 1 are strongly dependent on [2EH]. As $2 \mathrm{EH}$ is added to the $\mathrm{LiBr}$ solution, $\mathrm{E}$ initially increases with $[2 \mathrm{EH}]$ until $\mathrm{E}$ reaches a maximum value, $\mathrm{E}_{\mathrm{M}}$, where $[2 \mathrm{EH}]=[2 \mathrm{EH}]_{\mathrm{M}}$. Further addition of $2 \mathrm{EH}$ decreases $\mathrm{E}$. The variation in enhancement with concentration is shown in Figure 2, where $E$ is displayed as a function of $[2 \mathrm{EH}]$. The open circles in this figure are the experimental results from Table 1 . The experimental results in Figure 2 were used to estimate $E_{M}$ and $[2 \mathrm{EH}]_{M}$ using a straightforward (but theoretically unjustified) empirical interpolation. For [2EH] < $416 \mathrm{wppm}, \mathrm{E}$ increased with increasing $[2 \mathrm{EH}]$, indicating that $[2 \mathrm{EH}]_{\mathrm{M}}>416 \mathrm{wppm}$. This increase in $\mathrm{E}$ with [2EH] was represented by the line segment in Figure 2 having the positive slope. 


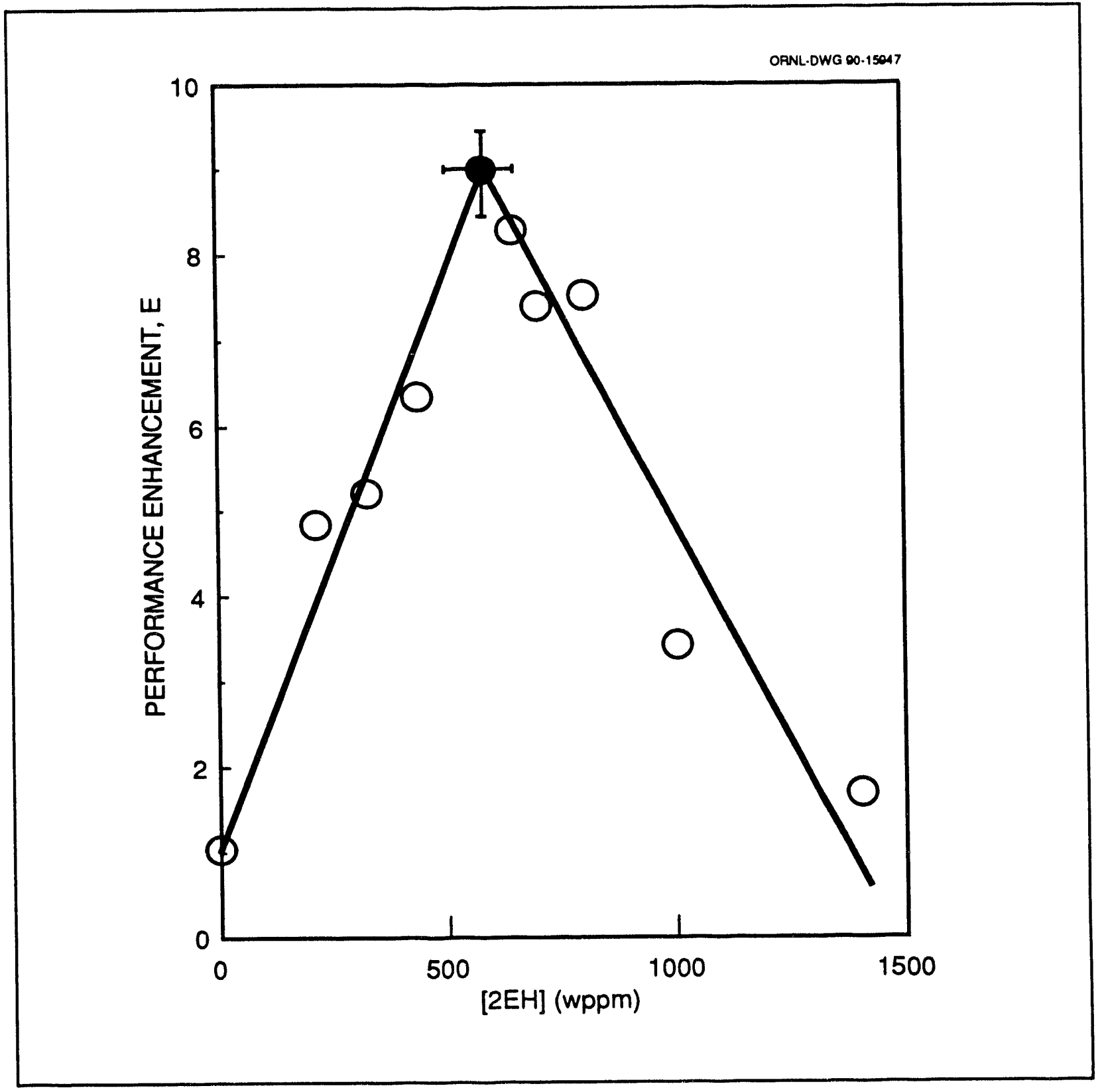

Fig. 2. Performance (mass transfer) enhancement, E, as a function of 2-ethyl-1hexanol concentration, [ $[\mathrm{EH}]$, in a static pool of aqueous $\mathrm{LiBr}$. The open circles are experimental measurements of performance enhancement, while the solid lines are empirical representations of the data. The solid circle is an estimate of the maximum performance enhancement, $E_{M}$. The error bars indicate the uncertainties in $E_{M}$ and $[2 \mathrm{EH}]_{M}$.

For $[2 \mathrm{EH}]>625$ wppm, $\mathrm{E}$ decreased with increasing $[2 \mathrm{EH}]$, indicating that $[2 \mathrm{EH}]_{\mathrm{M}}<$ $625 \mathrm{wppm}$. This decrease in $\mathrm{E}$ is represented by the line segment in Figure 2 having the negative slope. The two line segments intersected at the solid circle, which is the empirical 
estimate of $E_{M}$ and $[2 \mathrm{EH}]_{M}$. In Figure 2, $E_{M}=9.0$ and $[2 E H]_{M}=565$ wppm, within the uncertainties indicated by the error bars.

Similar static pool enhancement measurements were conducted using 1-heptanol (HEP), $1 \mathrm{H}, 1 \mathrm{H}, 7 \mathrm{H}$-dodecafluoro-1-heptanol (DFH), and 1,1,1-trifluoro-2-octanol (TFO) as performance additives. These results are summarized in Tables $2-4$, respectively. The performance enhancements obtained with HEP, DFH, and TFO also show a strong dependence on additive concentration. As with $2 \mathrm{EH}$, performance enhancement reaches a maximum value, $\mathrm{E}_{\mathrm{M}}$, at some optimum additive concentration. Estimates of $E_{M}$ and optimum additive concentrations are indicated in Tables $2-4$ for the respective additives. These values were obtained using the same interpolation procedure illustrated in Figure 2.

Table 2. Static performance enhancement, E, as a function of 1-heptanol concentration, [HEP] $]^{a, b}$

\begin{tabular}{|c|c|}
\hline $\begin{array}{c}{[\text { HEP] }} \\
\text { (wppm) }\end{array}$ & $\mathrm{E}$ \\
\hline 0 & 1.0 \\
\hline 205 & 4.6 \\
\hline 410 & 7.5 \\
\hline 580 & 6.8 \\
\hline 680 & 7.9 \\
\hline 680 & 7.9 \\
\hline 680 & 6.5 \\
\hline 825 & 4.8 \\
\hline
\end{tabular}

Initial Conditions: $[\mathrm{LiBr}]=60 \mathrm{wt} \%, \mathrm{~T}=20^{\circ} \mathrm{C}$.

${ }^{b} \mathrm{E}_{\mathrm{M}}=8.8,[\mathrm{HEP}]_{\mathrm{M}}=600 \mathrm{wppm}$.

Table 3. Static performance enhancement, E, as a function of $1 \mathrm{H}, 1 \mathrm{H}, 7 \mathrm{H}$-dodecafluoro-1-heptanol concentration, [DFH] $]^{a, b}$

\begin{tabular}{rl}
$\begin{array}{r}{[\mathrm{DFH}]} \\
(\text { wppm })\end{array}$ & $\underline{\mathrm{E}}$ \\
\hline 0 & 1.0 \\
225 & 2.5 \\
445 & 3.3 \\
880 & 4.4 \\
1326 & 2.0 \\
1760 & 0.4 \\
2640 & 0.5 \\
\hline
\end{tabular}

${ }^{\circ}$ Initial Conditions: $[\mathrm{LiBr}]=60 \mathrm{wt} \%, \mathrm{~T}=20^{\circ} \mathrm{C}$.

${ }^{b} \mathrm{E}_{\mathrm{M}}=5.0,[\mathrm{DFM}]_{\mathrm{M}}=730 \mathrm{wppm}$. 
Table 4. Static performance enhancement, E, as a function of 1,1,1-trifluoro-2-octanol concentration, [TFO] ${ }^{a, b}$

\begin{tabular}{rl}
\hline [TFO] & \\
(wppm) & $\underline{\mathrm{E}}$ \\
0 & 1.0 \\
260 & 1.8 \\
515 & 2.6 \\
645 & 2.8 \\
775 & 2.0 \\
1030 & 2.0 \\
\hline
\end{tabular}

${ }^{\circ}$ Initial Conditions: $[\mathrm{LiBr}]=60 \mathrm{wt} \%, \mathrm{~T}=20^{\circ} \mathrm{C}$.

${ }^{b} \mathrm{E}_{\mathrm{M}}=2.9,[\mathrm{TFO}]_{\mathrm{M}}=590 \mathrm{wppm}$.

The enhancement dependence on additive concentration observed in Figure 2 for $2 \mathrm{EH}$ and in Tables 2 through 4 for HEP, DFH, and TFO was also observed for the other additives. For each additive tested in the static pool, E initially increased with additive concentration, $X$, until a maximum enhancement, $E_{M}$, was obtained at an optimum additive concentration, $[\mathrm{X}]_{\mathrm{M}}$. For $[\mathrm{X}]>[\mathrm{X}]_{\mathrm{M}}, \mathrm{E}$ decreased with increasing $[\mathrm{X}]$. Each additive, $\mathrm{X}$, evaluated in the static pool tests could be characterized by $[X]_{M}$ and by $E_{M}$. The results of all screening studies (including those previously described in Tables 1 through 4) are summarized in Table 5. For the 12 additives, $X$, listed in column 1 of Table 5, the optimum additive concentration, $[\mathrm{X}]_{\mathrm{M}}$, is listed in column 2. The maximum performance enhancement, $\mathrm{E}_{\mathrm{M}}$, is listed in column 3. Most of the additives listed in this table were only slightly soluble in aqueous $\mathrm{LiBr}$ (solubility -100-800 wppm). The exceptions are noted in Table 5.

The values of $E_{M}$ in Table 5 vary from 1.6 to 9.1. For the most effective additives $\left(E_{M}>\right.$ 6), water vapor absorption was accompanied by agitation of the $\mathrm{LiBr}$ solution at the liquid/vapor interface. (Interfacial agitation was not observed in experiments with $\mathrm{LiBr}$ solutions not containing additives.) This additive-induced agitation has been observed by many other researchers. ${ }^{6,7}$ It has generally been attributed to Marangoni convection. (See Section 4 for alternate explanations of the additive enhancement mechanism.) This "Marangoni" agitation presumably increases the water absorption rate by helping mix $\mathrm{LiBr}$ solution near the liquid/vapor interface with $\mathrm{LiBr}$ solution far from the interface. ${ }^{13}$

Several experiments were performed to compare Marangoni agitation (due to performance additives) with mechanical agitation produced by stirring (using a magnetic "stirring bar"). The results of these experiments are summarized in Table 6. Mechanical agitation alone produced slightly less enhancement $\left(\mathrm{E}_{\mathrm{M}}=8.1\right)$ than did the performance additive, $2 \mathrm{EH}\left(\mathrm{E}_{\mathrm{M}}\right.$ $=9.0$ ). The combination of mechanical agitation and a performance additive produced slightly more enhancement $\left(E_{M}=9.3\right)$ than did $2 \mathrm{EH}$ alone $\left(\mathrm{E}_{\mathrm{M}}=9.0\right)$. 
Table 5. Maximum static enhancement, $E_{M}$, of various additives

\begin{tabular}{|c|c|c|}
\hline ADDITIVE, $X$ & $\begin{array}{c}{[\mathrm{X}]_{\mathrm{M}}} \\
\text { (wppm) }\end{array}$ & $\underline{E}_{M}$ \\
\hline $\begin{array}{l}\text { 2-Ethyl-1-hexanol } \\
\text { 1-Heptanol } \\
\text { 1H,1H,7H-Dodecafluoro-1-heptanol } \\
\text { 1,1,1-Trifluoro-2-octanol } \\
\text { 1-Octanol } \\
\text { 2-Octanol } \\
\text { 3-Octanol } \\
\text { 1-Decanol } \\
\text { 1-Octene-3-ol } \\
\text { 2,6-Dimethyl-4-heptanol } \\
\text { 2-Methyl-2-propanol } \\
\text { 1,2-Hexanediol } \\
\text { 1,6-Hexanediol } \\
\text { 2-Heptenal } \\
\text { 15-Crown-5 } \\
\text { Surfactant FC450 } \\
\text { Surfactant FC135 } \\
\text { Surfactant FC99s }\end{array}$ & $\begin{array}{r}565 \\
600 \\
730 \\
590 \\
680 \\
580 \\
600 \\
680 \\
520 \\
610 \\
3500 \\
780 \\
920 \\
604 \\
850 \\
790 \\
820 \\
760\end{array}$ & $\begin{array}{l}9.0 \\
8.8 \\
5.0 \\
2.9 \\
8.4 \\
7.9 \\
9.1 \\
7.4 \\
8.1 \\
5.0 \\
5.5 \\
2.8 \\
3.1 \\
5.0 \\
2.9 \\
2.8 \\
1.9 \\
1.6\end{array}$ \\
\hline \multicolumn{3}{|l|}{${ }^{\mathbf{s}}$ Soluble in $\mathrm{LiBr} / \mathrm{H}_{2} \mathrm{O}$ solution } \\
\hline ADDITIVE & STIRRING & $\underline{E}_{M}$ \\
\hline $2 \mathrm{EH}$ & Yes & 9.3 \\
\hline $2 \mathrm{EH}$ & No & 9.0 \\
\hline None & Yes & 8.1 \\
\hline None & No & 1.0 \\
\hline
\end{tabular}

The slight synergism between Marangoni agitation and mechanical agitation shown in Table 6 prompted the investigation of potential synergism between additives. The observed 
changes in performance when a second additive is combined with $2 \mathrm{EH}$ are summarized in Table 7. The results in this table indicate that essentially no changes in performance occur when either HEP or DFH are combined with 2EH. However, when 2-methyl-2-propanol (2MP) is combined with $2 \mathrm{EH}$, a $10 \%$ increase in performance occurs. Although the reason for the synergism between $2 \mathrm{EH}$ and $2 \mathrm{MP}$ is unknown, it may be that $2 \mathrm{MP}$ behaves differently from most other additives. Unlike the other additives in Table 7 and most of the effective additives evaluated in this study, $2 \mathrm{MP}$ is very soluble in aqueous $\mathrm{LiBr}$, and $2 \mathrm{MP}$ does not produce visible Marangoni convection.

Table 7. Effect of additive combination on performance enhancement

$\begin{array}{ccc}\text { ADDITIVE 1 } & \text { ADDITIVE 2 } & \mathrm{E}_{\mathrm{K}} \\ 2 \mathrm{EH} & \text { None } & 9.0 \\ 2 \mathrm{EH} & \text { HEP } & 8.8 \\ 2 \mathrm{EH} & \text { DFH } & 9.0 \\ 2 \mathrm{EH} & 2 \mathrm{MP} & 9.9\end{array}$

\subsection{Dynamic Performance Enhancement Results}

The static screening results led to the selection of (1) four additives: $2 E H, H E P, D F H$, and TFO and (2) a mixture of $2 \mathrm{EH}$ and $2 \mathrm{MP}$ for further testing in dynamic performance experiments. The additives chosen for further testing embodied some of the most desirable characteristics of all additives tested in the static pool. Two additives, 2EH and HEP, were selected for dynamic testing because of their excellent performance enhancement. Two other additives, DFH and TFO, were selected because of their (predicted) superior thermal and chemical stability. ${ }^{14}$ The mixture of $2 \mathrm{EH}$ and $2 \mathrm{MP}$ was evaluated because of the enhancement synergism observed in Table 7.

Each additive and additive mixture was evaluated for a range of concentrations in the minisorber using the experimental procedure described in the previous section. Dynamic performance enhancement was determined by comparing absorber heat transfer with and without additive. Results from a typical minisorber experiment are shown in Figure 3. In this figure, the enhancement ratio, $\mathrm{E}_{\mathrm{H}}$ (which is the ratio of the heat transfer coefficient with additive to the heat transfer coefficient without additive), is shown as a function of [2EH]. The circles are experimental results obtained at an absorber film temperature, $\mathrm{T}_{\mathrm{F}}=92^{\circ} \mathrm{C}$, with an $\mathrm{LiBr}$ solution flow rate, $\dot{\mathrm{m}}=603 \mathrm{~g} / \mathrm{min}$. Initially, $\mathrm{E}_{\mathrm{H}}=1$ with no additive present (by definition), then increased to a maximum value as [2EH] increased. Unlike the static pool measurements, further increases in $[2 \mathrm{EH}]$ did not change $\mathrm{E}_{\mathrm{H}}$. Within experimental 


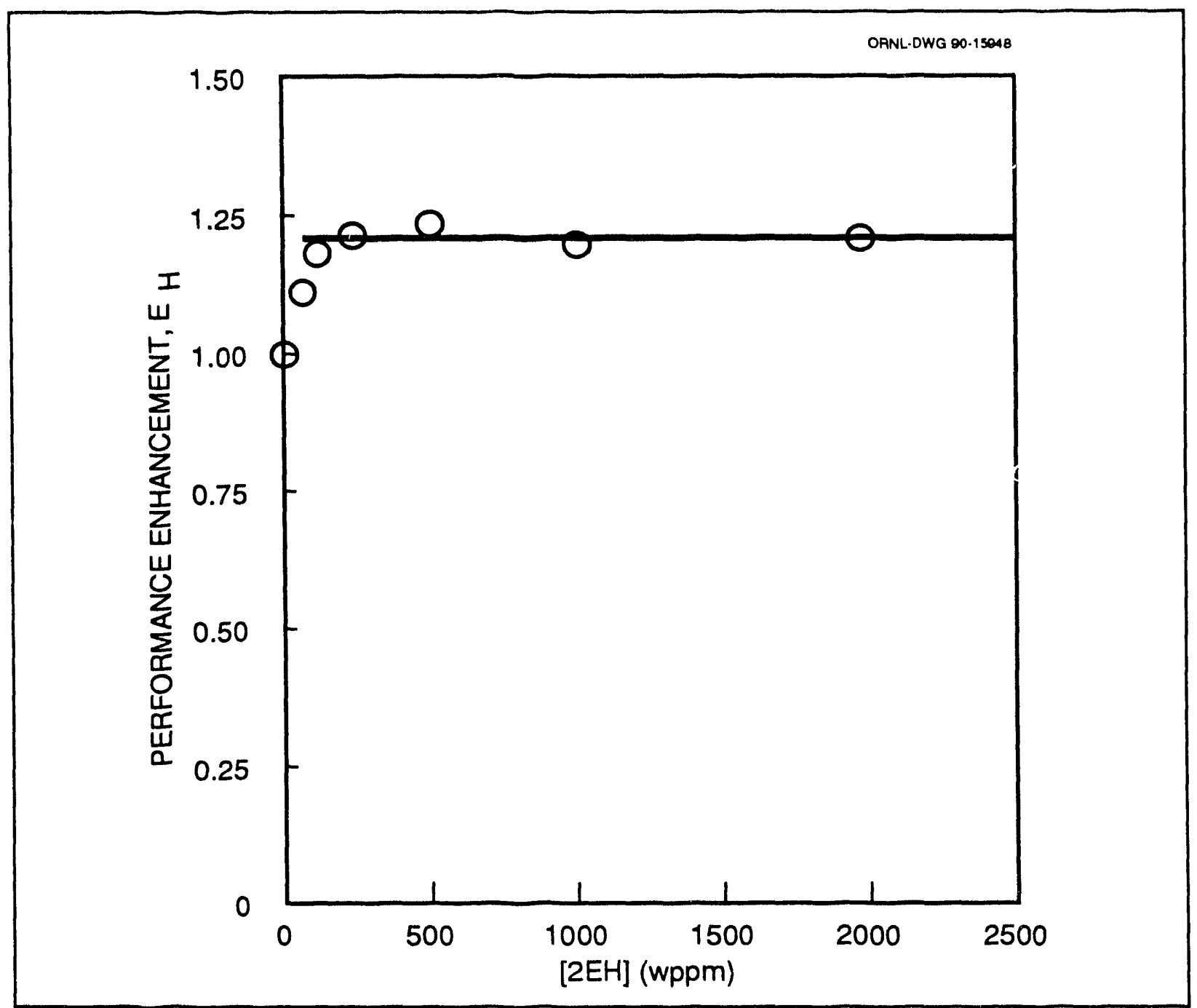

Fig. 3. Performance (heat transfer) enhancement, $E_{H}$, as a function of 2-ethyl-1. hexanol concentration, [ $2 \mathrm{EH}$ ], in a falling film absorber. The circles are experimental results obtained at $T_{F}=92^{\circ} \mathrm{C}$ and $\dot{\mathbf{m}}=603 \mathrm{~g} / \mathrm{min}$. The solid line is the average performance enhancement, $\overline{\mathrm{E}}_{\mathrm{H}}$.

uncertainty, $\mathrm{E}_{\mathrm{H}}$ remained constant above a threshold [2EH]. Above the threshold [2EH], the average performance enhancement, $\overline{\mathrm{E}}_{\mathrm{H}}$, was $\overline{\mathrm{E}}_{\mathrm{H}}=1.19 \pm 0.01$ as indicated by the solid horizontal line in Figure 3. 
The enhancement results in Figure 3 were typical of the behavior observed in minisorber experiments for other effective performance additives. The average dynamic enhancement, $\overline{\mathbf{E}}_{\mathrm{H}}$, was relatively independent of $[\mathrm{X}]$ for additive concentrations above a threshold value. (This insensitivity to additive concentration is consistent with other falling film enhancement studies. ${ }^{9}$ ) However, $\overline{\mathrm{E}}_{\mathrm{H}}$ did vary slightly with $\mathrm{T}_{\mathrm{F}}$ and significantly_with $\dot{\mathbf{m}}$. Therefore, in order to compare the performance enhancement of different additives, $\overline{\mathbf{E}}_{\mathrm{H}}$ was evaluated for similar $T_{F}$ and $\dot{m}$. The results of the dynamic performance evaluations are summarized in Table 8 . Qualitatively similar results were obtained at other mass flow rates. The results in this table indicate that only $2 \mathrm{EH}, \mathrm{HEP}$, and $\mathrm{DFH}$ showed sufficient enhancement $\left(\mathrm{E}_{\mathrm{H}}>1\right)$ to warrant further evaluation.

Table 8. Minisorber performance enhancement of various additives ${ }^{a}$

\begin{tabular}{cc}
\hline ADDITIVE(S) & $\overline{\overline{\mathrm{E}}_{11}}$ \\
\hline $2 \mathrm{EH}$ & $1.19 \pm .01$ \\
HEP & $1.25 \pm .04$ \\
DFH & $1.07 \pm .01$ \\
TFO & $0.95 \pm .03^{b}$ \\
$2 \mathrm{EH} \&$ 2MP & $0.74 \pm .05^{c}$ \\
\hline
\end{tabular}

absorber operating conditions at $\mathrm{T}=96^{\circ} \mathrm{C}$ and $\dot{\mathbf{m}}=605 \mathrm{~g} / \mathrm{min}$.

${ }^{b} \mathrm{E}_{\mathrm{H}}$ decreased with increasing [TFO].

${ }^{\circ} \mathrm{E}_{\mathrm{H}}$ decreased with increasing [2MP].

\subsection{Thermal and Chemical Stability Results}

Only 2EH, HEP, and DFH were deemed sufficiently effective (Table 8) to justify the evaluation of their thermal and chemical stability. The relative thermal stability of these additives was evaluated by determining onset temperatures, $T_{R}$, using the DSC. A typical thermal stability evaluation is shown in Figure 4. In this figure, the heat flowing into a $2 \mathrm{EH}$ sample is shown as a function of the sample temperature as the DSC is slowly heated at a constant rate $\left(10^{\circ} \mathrm{C} / \mathrm{min}\right)$. The peak at $224^{\circ} \mathrm{C}$ is due to heat generated from the thermal decomposition of $2 \mathrm{EH}$. The arrow at $\mathrm{T}_{\mathrm{R}}=207^{\circ} \mathrm{C}$ indicates the onset of thermal decomposition for $2 \mathrm{EH}$. The relative thermal stability of HEP and DFH were determined in a similar manner.

The relative chemical stability of a particular additive depends on the other chemicals-primarily the corrosion inhibitor-present in the absorber fluid. ${ }^{2}$ An initial estimate of chemical stability was determined for specific additive/inhibitor mixtures. Each additive was mixed with a sufficient amount of corrosion inhibitor (either chromate or molybdate) to oxidize each additive to yield the corresponding carboxylic acid. ${ }^{15}$ (This computation was used only to compare similar molar quantities of the various performance 


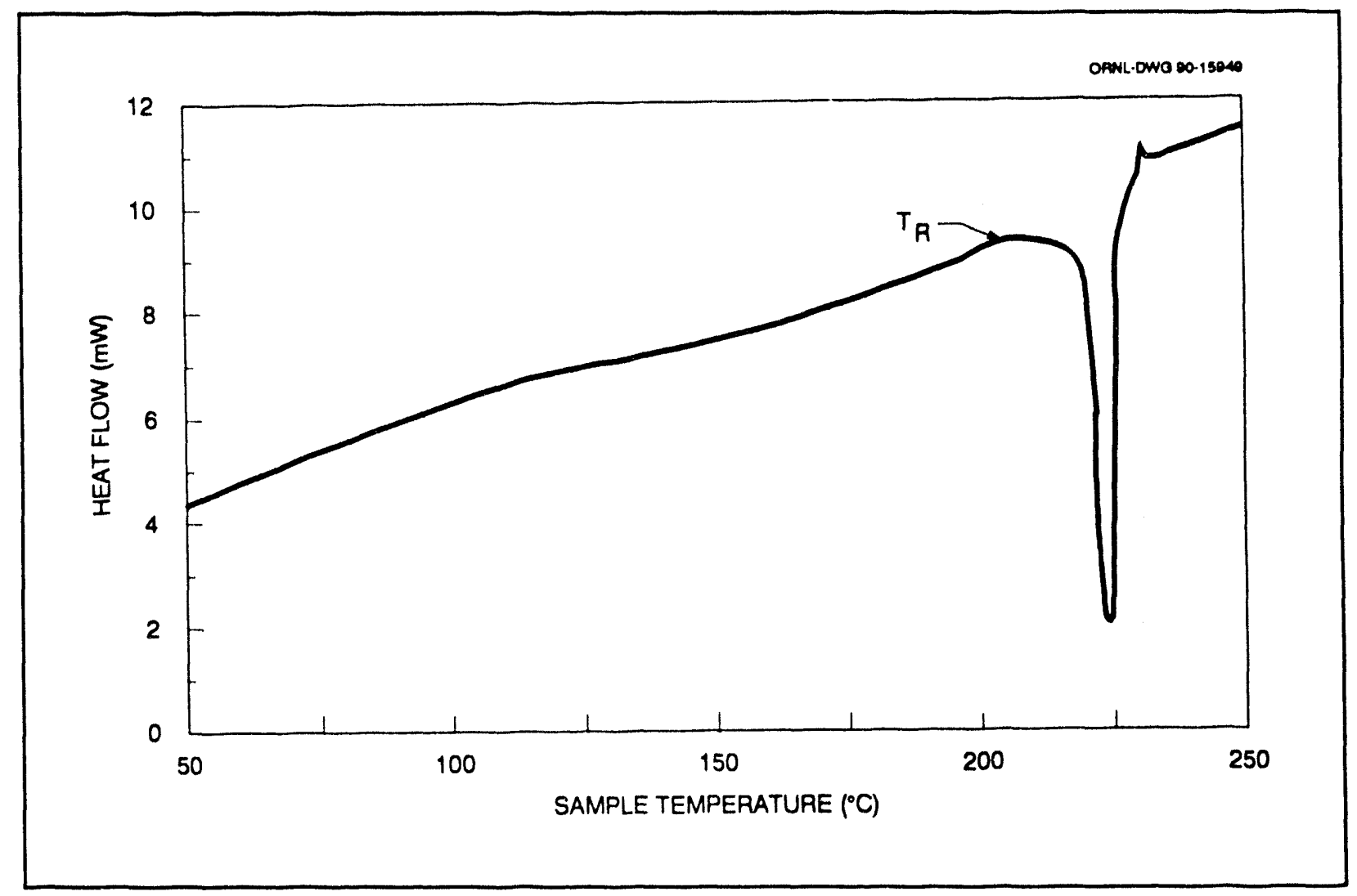

Fig. 4. Thermal stability of 2EH (2-ethyl-1-hexanol) obtained by DSC (differential scanning calorimetry). The heat flow rate into a $2 \mathrm{EH}$ sample is shown as a function of temperature as the DSC is slowly heated $\left(\right.$ at $\left.10^{\circ} \mathrm{C} / \mathrm{min}\right)$. The peak at $225^{\circ} \mathrm{C}$ indicates a sample enthalpy change due to thermal decomposition. The arrow at $T_{R}=207^{\circ} \mathrm{C}$ indicates the onset of thermal decomposition.

additives and corrosion inhibitors. No assumptions about the nature or stoichiometry of the reactions involved were made).

A typical DSC for one specific additive/inhibitor mixture is shown in Figure 5. In this figure, heat flowing into a mixture of HEP and $\mathrm{K}_{2} \mathrm{CrO}_{4}$ is shown as a function of DSC temperature. The peak at $218^{\circ} \mathrm{C}$ is due to HEP's reaction with $\mathrm{K}_{2} \mathrm{CrO}_{4}$. The arrow at $\mathrm{T}_{\mathrm{R}}=$ $210^{\circ} \mathrm{C}$ indicates the onset of $\mathrm{HEP}$ 's reaction with $\mathrm{Li}_{2} \mathrm{CrO}_{4}$. The relative chemical stabilities of the other additives with chromate and molybdate were determined in a similar manner.

The results of thermal and chemical stability evaluations of these three additives are summarized in Table 9. For the test conditions indicated in column $1, \mathrm{~T}_{\mathrm{R}}$ is listed for $2 \mathrm{EH}$, HEP, and DFH in columns 2-4, respectively. The test conditions evaluated include additive alone (for an indication of thermal stability), additive/inhibitor mixtures (for a preliminary indication of chemical stability), and additive/inhibitor mixtures in an aqueous $\mathrm{LiBr}$ solution (to more closely simulate the actual chemical environment expected during generator operation). Table 9 indicates that, as expected, the stability of DFH is much better than that of either HEP or $2 \mathrm{EH}$. The stability of HEP is also slightly better than that of $2 \mathrm{EH}$. At the test conditions listed in the last row of Table $9, T_{R}$ for HEP is $11^{\circ} \mathrm{C}$ greater than $T_{R}$ for $2 \mathrm{EH}$. 


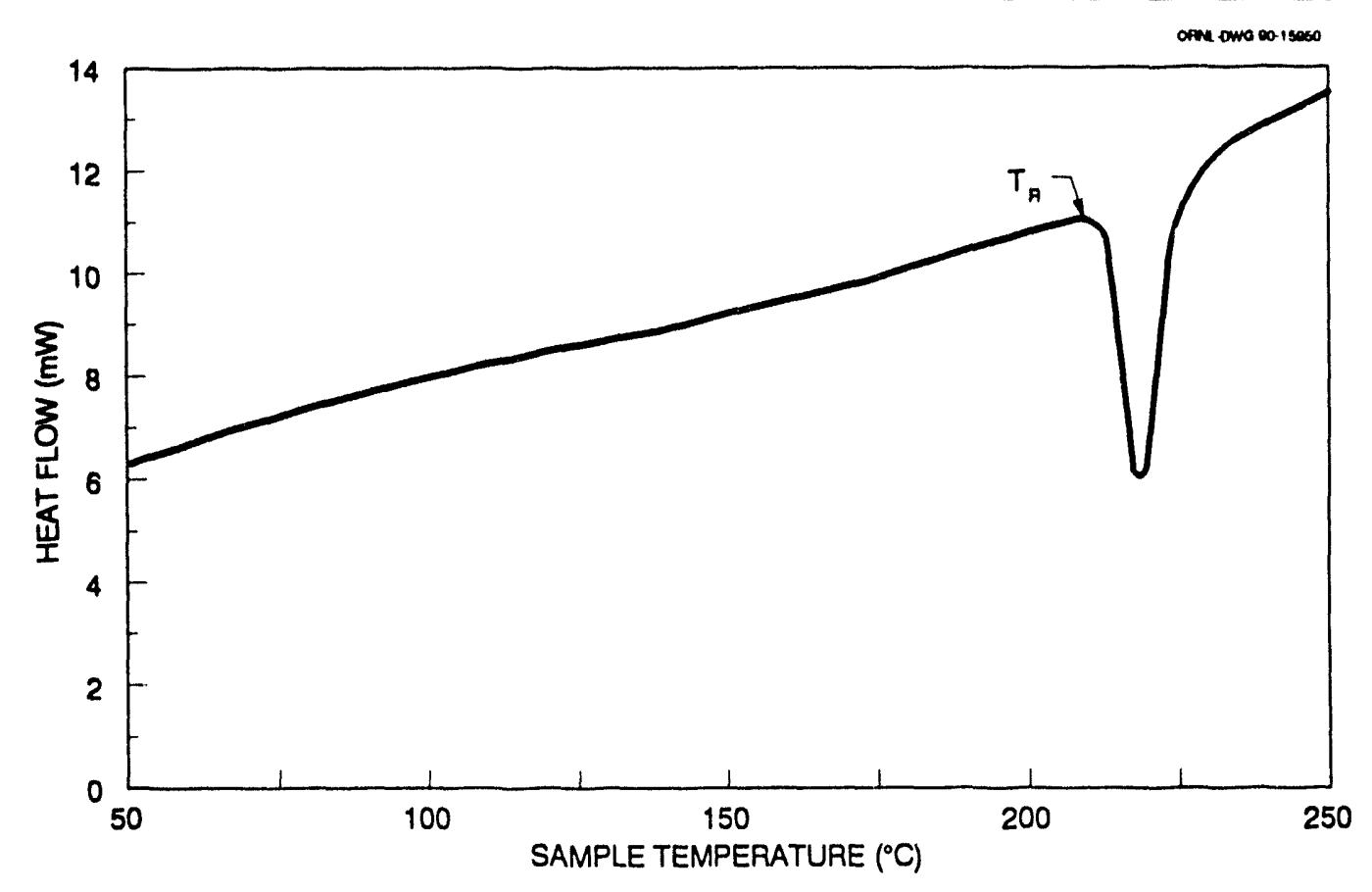

Fig. 5. Chemical stability of 1-heptanol(HEP)-chromate mixture obtained by DSC (differential scanning calorimetry). The heat flow into a mixture of HEP and $\mathrm{K}_{2} \mathrm{CrO}_{4}$ is shown as a function of sample temperature as the DSC is slowly heated (at $10^{\circ} \mathrm{C} / \mathrm{min}$ ). The peak at $218^{\circ} \mathrm{C}$ indicates a mixture enthalpy change caused by reaction. The arrow at $T_{R}=210^{\circ} \mathrm{C}$ indicates the onset of chemical reaction.

Table 9. Stability of performance additives in various environments

TEST CONDITIONS

Additive only

Additive $+\mathrm{K}_{2} \mathrm{CrO}_{4}$

Additive $+\mathrm{Na}_{2} \mathrm{MoO}_{4}$

Additive $+\mathrm{K}_{2} \mathrm{CrO}_{4}+\left(\mathrm{H}_{2} \mathrm{O}+\mathrm{LiBr}\right)^{a}$

Additive $+\mathrm{Na}_{2} \mathrm{MOO}_{4}+\left(\mathrm{H}_{2} \mathrm{O}+\mathrm{LiBr}\right)^{a}$
ADDITIVE REACTION ONSET

TEMPERATURE, $\mathrm{T}_{\mathrm{R}}\left({ }^{\circ} \mathrm{C}\right)$

$\underline{2 E H} \quad \underline{H E P} \quad \underline{\mathrm{DFH}}$

$207 \quad 216 \quad>300$

$198 \quad 210 \quad>300$

$200 \quad 203 \quad>300$

$249 \quad>245^{b} \quad$-.

$230^{c} \quad 241$

${ }^{\circ} 60$ wt \% $\mathrm{LiBr}, 0.1$ wt \% $\mathrm{LiOH}$ in $\mathrm{H}_{2} \mathrm{O}$; $\mathrm{LiBr}$ solution is $45 \%$ of total sample weight.

'Experiment terminated to limit $\mathrm{H}_{2} \mathrm{O}$ pressure in sample capsule.

$\mathrm{LiBr}$ sclution is $25 \%$ of total sample weight. 
These test conditions more closely simulate the chemical environment anticipated during generator operation in the advanced chiller because the additive and corrosion inhibitors have been diluted with $\mathrm{LiBr}$ solution. (The alkalinity was also adjusted to closely represent alkalinity anticipated in generator operation. ${ }^{2}$ ) However, even at these conditions, the corrosion inhibitor concentrations in Table 9 are 200 to 2000 times greater than anticipated in the high temperature generator.

As indicated in rows 4 and 5 of Table 9, after aqueous $\mathrm{LiBr}$ solutions were added to specific additive/inhibitor mixtures, reaction onset temperatures increased $30^{\circ} \mathrm{C}$ to $40^{\circ} \mathrm{C}$. The increases in $\mathrm{T}_{\mathrm{R}}$ for a particular additive/inhibitor were approximately proportional to the quantity of added $\mathrm{LiBr}$ solution, indicating that the $\mathrm{LiBr}$ solution was acting as an inert diluent. As expected, the additive's reaction with a corrosion inhibitor depends on the concentration of corrosion inhibitor in the LiBr solution.

Unfortunately, because of experimental difficulties it was not possible to evaluate the dependence of $T_{R}$ on corrosion inhibitor concentration at more realistic conditions. When $\mathrm{LiBr}$ solutions were added to the DSC sample capsules, the vapor pressure of water exceeded the capsule pressure limit at temperatures above $240^{\circ} \mathrm{C}$. When this limit was exceeded, the capsules would occasionally rupture and contaminate the DSC. Because of this problem, the higher onset temperatures of more dilute solutions (which would be more representative of actual generator conditions) could not be studied. 


\section{DISCUSSION}

\subsection{Static Performance Enhancement}

Determining the mechanism(s) responsible for performance enhancement is difficult because of the apparent complexity of the interactions and the dearth of definitive experimental results. Different mechanisms describing the role of additives in heat and mass transfer have been proposed. Several studies attribute the performance enhancement to agitation of the solution at the vapor interface produced by Marangoni convection. ${ }^{6-9} \mathrm{~A}$ catalytic mechanism, by which the activation energy of absorption is reduced by the additive, has also been proposed. ${ }^{16}$ Other explanations for the performance enhancement postulate that additives may clean the heat exchanger surface or that additives may promote dropwise condensation. ${ }^{5}$

Although several mechanisms have been proposed to explain how additives enhance heat and mass transfer, the results in this study seem most consistent with Marangoni-induced convection in the static pool. For almost all of the effective additives evaluated in Table 5, performance enhancement was strongly correlated with agitation of the $\mathrm{LiBr}$ solution surface. The more surface agitation, the more performance enhancement. The mechanical stirring results in Table 6 also seem consistent with Marangoni-induced agitation. The maximum enhancement produced by mechanical stirring is only slightly smaller than the enhancement produced by the performance additive $2 \mathrm{EH}$. The enhancement produced by a combination of additive and mechanical stirring is also not significantly better than that produced by $2 \mathrm{EH}$ alone. The results in Table 6 suggest that most of the enhancement $(-90 \%)$ from $2 \mathrm{EH}$ is due to agitation of the $\mathrm{LiBr}$ solution.

The behavior of most of the effective additives evaluated in this study was similar to that of $2 \mathrm{EH}$. One additive which behaved differently was $2 \mathrm{MP}$. In static pool experiments, $2 \mathrm{MP}$ enhanced performance but did not produce surface agitation. As indicated in Table 7, 2MP was also the only additive which had a synergistic effect when coupled with $2 \mathrm{EH}$. Since 2MP is completely soluble in aqueous $\mathrm{LiBr}$, no second phase of 2MP forms at the solution/vapor interface. This second phase is thought to be necessary for Marangoni agitation. ${ }^{6,17}$ Perhaps 2MP enhances heat and mass transfer by reducing the activation energy of absorption (as proposed by Biermann). ${ }^{16}$ Another possibility is that $2 \mathrm{MP}$ changes some fluid transport property, such as viscosity.

\subsection{Dynamic Performance Enhancement}

Comparison of Tables 5 and 8 indicates general qualitative agreement between static and dynamic enhancement results for the additives evaluated by both methods. (Quantitative agreement is not expected because of differences in testing conditions-film thickness, vapor residence time, fluid velocity, etc. ${ }^{5}$ ) The additives producing the most static enhancement, 2EH and HEP, also produce the most dynamic enhancement. The additive producing the least static enhancement, TFO, also produced the least dynamic enhancement. The static and dynamic performance enhancement of DFH was intermediate between TFO and HEP.

One significant disparity between static and dynamic results was in the behavior of the 2EH/2MP mixture. In the static tests (summarized in Table 7), this mixture enhanced performance approximately $10 \%$ more than did $2 \mathrm{EH}$ alone. However, in the dynamic 
performance tests (Table 8), addition of $2 \mathrm{MP}$ to $2 \mathrm{EH}$ decreased heat and mass transfer to $\mathrm{E}_{\mathrm{H}}$ $<1$. One possible explanation for this disparity is the high solution temperature in the minisorber $\left(96^{\circ} \mathrm{C}\right)$ relative to that of the static $\mathrm{LiBr}$ pool $\left(20^{\circ} \mathrm{C}\right)$. Because $2 \mathrm{MP}$ boils at $83^{\circ} \mathrm{C},{ }^{18}$ most of the $2 \mathrm{MP}$ added to the $\mathrm{LiBr}$ solution in the minisorber probably vaporized. The presence of a high partial pressure of $2 \mathrm{MP}$ in the minisorber should inhibit water vapor absorption in the same manner that inert gases inhibit water vapor absorption. If the minisorber could have been operated at a lower temperature, more 2MP would have remained in solution and, perhaps, improved absorber performance.

\subsection{Thermal and Chemical Stability}

This study was directed toward testing additives structurally similar to $2 \mathrm{EH}$ but having slightly greater thermal stability. This experimental approach was justified because previous measurements by other researchers indicated that $2 \mathrm{EH}$ had satisfactory thermal and chemical stability at generator temperatures near $220^{\circ} \mathrm{C} .{ }^{11}$ (These previous measurements suggest that $2 \mathrm{EH}$ might even be satisfactory at advanced chiller temperatures with some modifications in chiller design. ${ }^{5}$ See Section 4.4.) Generally, the thermal stability of aliphatic compounds (1) increases slightly as the number of carbon atoms decreases and (2) increases significantly as fluorine is substituted for hydrogen. ${ }^{19}$

The thermal results in Table 9 agree with these predictions. The thermal stability of HEP (which contains seven carbon atoms) is slightly greater than that of $2 \mathrm{EH}$ (which contains eight carbon atoms). The thermal stability of the fluorinated additive, DFH, is significantly greater than that of the unfluorinated additive, HEP. Although the presence of a corrosion inhibitor or $\mathrm{LiBr}$ solution changes $\mathrm{T}_{R}$, the additives in Table 9 have a similar hierarchy in chemical and thermal stability. For a particular corrosion inhibitor, DFH is much more stable than HEP, which is slightly more stable than $2 \mathrm{EH}$.

For $2 \mathrm{EH}$, Table 9 shows that chromate is a slightly more reactive inhibitor than molybdate. In previous studies, differences between chromate and molybdate reactivity were more pronounced. For example, one study showed significant $2 \mathrm{EH}$ reaction with $\mathrm{Li}_{2} \mathrm{CrO}_{4}$ at $180^{\circ} \mathrm{C}$, ${ }^{1}$ while another study showed only moderate $2 \mathrm{EH}$ reactivity with $\mathrm{Li}_{2} \mathrm{MoO}_{4}$ at $220^{\circ} \mathrm{C} .{ }^{11}$ The apparent discrepancy between Table 9 and the earlier results is due to differences in inhibitor concentration. When $\mathrm{Li}_{2} \mathrm{CrO}_{4}$ is used as a corrosion inhibitor in $\mathrm{LiBr}$, a typical concentration is $2700 \mathrm{wppm}$ 'typical $\mathrm{Li}_{2} \mathrm{MoO}_{4}$ concentration in $\mathrm{LiBr}$ is $300 \mathrm{wppm} .{ }^{11}$ Since reactivity is strongly dependent on concentration, ${ }^{2}$ the greater inhibitor concentration (factor of 12 on a molar basis) partially explains the increased chromate reactivity. The remaining difference in reactivity is due to chromate's being a stronger oxidizing agent than molybdate. ${ }^{20}$

The results in Table 9 provide relative stability estimates of various inhibitor/additive combinations. The higher the $\mathrm{T}_{\mathrm{R}}$, the more stable the inhibitor/additive conbination. The results in Table 9 can also be combined with previous stability measurements to crudely estimate additive decomposition rates. For example, in a previous stability study, approximately $7 \%$ of the $2 \mathrm{EH}$ in an $\mathrm{LiBr}$ solution containing $\mathrm{Li}_{2} \mathrm{MoO}_{4}$ decomposed after 168 hours at $227^{\circ} \mathrm{C} .{ }^{11}$ Since HEP in molybdate is slightly more stable than $2 \mathrm{EH}$ in molybdate, less additive decomposition would be expected if HEP were evaluated at similar conditions. (At the most representative conditions in Table $9, \mathrm{~T}_{\mathrm{R}}$ is $\sim 11^{\circ} \mathrm{C}$ greater for HEP than for $2 \mathrm{EH}$.) No additive decomposition would occur if $\mathrm{DFH}$ were evaluated at these generator conditions. 


\subsection{Implications for Advanced Chiller Development}

Ideally, potential additives for the advanced chiller would have superior performance enhancement as well as superior thermal and chemical stability. Unfortunately, the results in Tables 5 and 8 indicate that a compromise between stability and performance may be required. Table 5 indicates that the performance enhancement of HEP is slightly better than that of $2 \mathrm{EH}$, which is significantly better than that of $\mathrm{DFH}$. However, Table 8 indicates that the stability of DFH is significantly better than that of either HEP or 2EH. If HEP has sufficient stability, it would produce more enhancement than DFH in the advanced chiller. The discussion in the previous paragraph suggests that HEP may be satisfactory at generator temperatures between $220^{\circ} \mathrm{C}$ and $235^{\circ} \mathrm{C}$.

We are unaware of any obvious, fundamental reason for the apparent compromise between additive stability and performance. Perhaps more potential performance additives need to be evaluated. A candidate additive may exist that has both superior performance enhancement and thermal stability.

Some technical problems associated with alcohol decomposition at high temperatures may be overcome by design modifications. At the lower limit of the desired generator temperature $\left(-220^{\circ} \mathrm{C}\right)$, HEP may have satisfactory thermal stability if $\mathrm{Li}_{2} \mathrm{MoO}_{4}$ can be used as a corrosion inhibitor. Higher generator temperatures may be possible if additional additive can be supplied to the absorption solution or if additive can be separated from the absorber solution before the solution enters the generator. Adequate purge capacity would also be required to remove volatile decomposition byproducts. The effects of nonvolatile decomposition products on heat and mass transfer must also be considered. Decomposition products could "poison" the additive enhancement or even coat heat exchanger surfaces. (Fortunately, some previous experiments indicate that this is not often a problem. ${ }^{17}$ ) Each of these design strategies will be evaluated in the advanced chiller development program. ${ }^{5}$

If, after applying the design modifications described in the previous paragraph, HEP still has insufficient thermal stability, DFH could be used as a performance additive in the advanced chiller. Although LFH has adequate thermal stability, the performance enhancement of DFH is significantly less than that of either HEP or $2 \mathrm{EH}$. Fortunately, the performance enhancement of DFH may also be improved by a different modification of the advanced chiller design. The results in Table 6 show that most of the performance enhancement of $2 \mathrm{EH}$ (and presumably, HEP) can be recovered by agitation at the solution/vapor interface. In the static pool experiments, mechanical agitation (stirring) improved heat and mass transfer almost as effectively as did a performance additive. Similar mechanical agitation could be accomplished in the advanced chiller by modifying the heat exchanger surfaces in the absorber. For example, using absorber tubes with noncylindrical cross-sections and adding fins or turbulence promoters to the tube surfaces might increase agitation at the solution/vapor interface. Such modifications have been used successfully to improve heat and mass transfer in another $\mathrm{LiBr}$-water absorber. ${ }^{21}$ 


\section{CONCLUSIONS}

The effectiveness and stability of potential performance additives in the advanced $\mathrm{LiBr}$ chiller were evaluated in a series of experimental studies. These studies of additive effectiveness and stability were necessary because many current performance additives decompose at the high generator temperatures desired in the advanced $\mathrm{LiBr}$ chiller $\left(220^{\circ} \mathrm{C}\right.$ to $260^{\circ} \mathrm{C}$ ). These stability problems can be mitigated by using less reactive corrosion inhibitors such as $\mathrm{Li}_{2} \mathrm{MoO}_{4}$ and by using more stable performance additives such as HEP or DFH.

A trade-off seems to exist between additive stability and effectiveness: the most effective performance additives are not the most stable additives. These studies indicate that HEP or $\mathrm{DFH}$ may be effective additives in the advanced $\mathrm{LiBr}$ chiller if $\mathrm{Li}_{2} \mathrm{MoO}_{4}$ is used as a corrosion inhibitor-HEP provides the greatest performance enhancement, and DFH provides the best thermal and chemical stability.

Some technical problems associated with alcohol decomposition at high temperature may be overcome by design modifications. Higher generator temperatures may be possible if additional additive can be supplied to the absorption solution or if additive can be separated from the absorber solution before the solution enters the generator. Adequate purge capacity would also be required to remove volatile decomposition byproducts. Effects of nonvolatile decomposition byproducts must also be considered. Each of these design strategies will be evaluated in the advanced chiller development program.

Performance enhancement measurements indicate that enhancement is strongly correlated with solution agitation. Although several mechanisms have been proposed to explain how additives enhance heat and mass transfer, the results seem most consistent with Marangoni-induced convection in the static pool. The most effective performance additives produced the most agitation at the solution/vapor interface. In the static pool experiments, mechanical agitation improved heat and mass transfer almost as effectively as did a performance additive. Similar mechanical agitation could be accomplished in the advanced chiller by modifying the heat exchanger surfaces in the absorber. This design strategy may also be evaluated in the advanced chiller development program. 


\section{REFERENCES}

1. Absorption Operation Maintenance, AM-FND4-772, The Trane Co., LaCrosse, Wisc., 1972.

2. R. H. Krueger, K. F. Dockus, and W. F. Rush, "Lithium chromate: Corrosion inhibitor for lithium bromide absorption refrigeration systems," ASHRAE Journal 6, 40-44 (1964).

3. R. C. DeVault, "Triple Effect Absorption Chiller Utilizing Two Refrigeration Circuits," U.S. patent 4,732,008, March 1988.

4. "Development and Proof-Testing of Basic Technology Needed for High Temperature Operation of $\mathrm{LiBr} / \mathrm{H}_{2} \mathrm{O}$ for Absorption Chiller Cycles," Request for Proposal No. SF416-87, Martin Marietta Energy Systems, Inc., May 24, 1990.

5. F. A. Creswick and R. H. Reiner, Absorber Research Plan for Water-Based Refrigerant Systems, ORNL/CF-90/342, Oak Ridge Natl. Lab., Martin Marietta Energy Systems, Inc., August 10, 1990.

6. T. Kashiwagi, "Basic Mechanism of Absorption Heat and Mass Transfer Enhancement by the Marangoni Effect," vresented at the Advanced Absorption Workshop, Knoxville, Tenn., Oct. 4, 1988.

7. Y. Elkassabgi and H. Perez-Blanco, "Experimental Study of the Effects of Alcohol Additives in Lithium Bromide Water Pool Absorbers," to be presented at ASHRAE Summer Meeting, June 1991.

8. T. Zawacki, S. Leipziger, and S. A. Weil, "Inducement of Convective Motion in Static Absorbers," presented at Fourth Joint Chemical Engineering Conference, Vancouver, B.C., September 1973.

9. T. Kashiwagi, et al., "Marangoni Effect in the Process of Steam Absorption into the Falling Film of the Aqueous Solution of $\mathrm{LiBr}$," presented at the Advanced Absorption Workshop, Knoxville, Tenn., Oct. 4, 1988.

10. A. Zaltash, M. R. Ally, and R. L. Linkous, Summary of the Experiments and Results to Evaluate the Effects of Additives on LiBr Solutions, ORNL/CF-90/369, Oak Ridge National Laboratory, Martin Marietta Energy Systems, Inc., December 1990.

11. "Development and Proof-Testing of Advanced Absorption Refrigeration Cycle Concepts - II," Task Report R87-852258-1, Carrier Corporation, November 1987, p. 26.

12. B. A. Tompkins, Analytical Chemistry Division, Oak Ridge National Laboratory, "Progress on Test Plan for Heat Transfer Additive Stability Study," letter to R. H. Reiner, Energy Division, Oak Ridge Natl. Lab., August 29, 1990.

13. G. Grossman, "Heat and Mass Transfer in Film Absorption," pp. 219-223 in Handbook of Heat and Mass Transfer, ed. N. T. Cheremisinoss, Gulf Publishing Co., Houston, Tex., 1986.

14. R. Modahl and P. J. Lynch, "Absorption Heat Exchange Systems, Methods and Absorbent Compositions," U.S. patent 3,783,631, January 1974.

15. R. T. Morrison and R. N. Boyd, Organic Chemistry, Allyn and Bacon, Boston, 1966, pp. 533-536.

16. W. J. Biermann, Additives for Enhancing Heat/Mass Transfer in Absorbers, Oak Ridge Natl. Lab., Martin Marietta Energy Systems, Inc., unpublished data, July 1984.

17. R. Modahl, Trane Corporation, personal communication to R. H. Reiner, Oak Ridge National Laboratory, July 1990.

18. R. T. Morrison and R. N. Boyd, Organic Chemistry, Allyn and Bacon, Boston, 1966, p. 501. 
19. R. T. Morrison and R. N. Boyd, Organic Chemistry, Allyn and Bacon, Boston, 1966, pp. 461-492.

20. H. M. Uhlig, Corrosion and Corrosion Control, J. Wiley, New York, 1963, pp. 224-232.

21. R. L. Webb and L. J. Mougin, "Apparatus for Absorbing a Vapor in a Liquid and Absorption Refrigeration System Incorporating Same," U.S. patent 4,223,539, June 1978. 


\section{INTERNAL DISTRIBUTION}

1. M. R. Ally

2. V. D. Baxter

3. R. S. Carlsmith

4. F. C. Chen

5. G. E. Courville

6. F. A. Creswick

7. R. C. DeVault

8. P. D. Fairchild

9. S. K. Fischer

10. W. Fulkerson

11. P. S. Gillis

12. M. A. Hensley

13. P. J. Hughes

14. M. A. Kuliasha

15. W. P. Levins

16. V. C. Mei

17. W. A. Miller
18. W. R. Mixon

19. R. W. Murphy

20. D. E. Reichle

21-45. R. H. Reiner

46. C. K. Rice

47. M. W. Rosenthal

48. J. R. Sand

49. R. B. Shelton

50. J. A. Shonder

51. J. N. Stone

52. E. A. Vineyard

53. A. Zaltash

54-55. Laboratory Records Department

56. Laboratory Records-RC

57. ORNL Patent Office

58. Central Research Library

59. Document Reference Section

\section{EXTERNAL DISTRIBUTION}

60. D. A. Ball, Battelle Columbus Laboratories, 505 King Avenue, Columbus, OH 43201-2693

61. F. Bawel, c/o Phillips Engineering Company, 721 Pleasant Street, St. Joseph, MI 49085

62. E. W. Becker, Southern California Gas Company, P.O. Box 3249, Terminal Annex, Mail Location 731-D, Los Angeles, CA 90051

63. W. J. Biermann, 45 Foxcroft Drive, Fayetteville, NY 13066

64. U. Bonne, Honeywell Corporate Technology Center, 10701 Lyndale Avenue South, Boomington, MN 55420

65. B. G. Buchanan, Computer Science Department, University of Pittsburgh, 206 Mineral Industries Building, Pittsburgh, PA 15260

66. R. Cohen, Ray W. Herrick Laboratories, Purdue University, West Lafayette, IN 47907 
67. D. D. Colosimo, Mechanical Technology, Inc., 968 Albany-Shaker Road, Latham, NY 12110

68. R. Crawford, Air Conditioning and Refrigeration Center, University of Illinois, 1200 W. Green Street, Urbana, IL 61801

69. J. Cuttica, Gas Research Institute, 8600 West Bryn Mawr Avenue, Chicago, IL 60631

70. K. Davidson, Gas Research Institute, 8600 West Bryn Mawr Avenue, Chicago, IL 60631

71. A. C. DeVuono, Battelle, Columbus Division, 505 King Avenue, Columbus, OH 43201-2693

72. D. A. Didion, National Institute of Standards \& Technology, CBT, Gaithersburg, MD 20899

73. W. Dolan, Gas Research Institute, 8600 West Bryn Mawr Avenue, Chicago, IL 60631

74. D. C. Erickson, Energy Concepts Co., 627 Ridgely Ave., Annapolis, MD 21401

75. R. J. Fiskum, CE-422, 5H-048/FORS, U.S. Department of Energy, Washington, DC 20585

76. S. Freedman, Gas Research Institute, 8600 West Bryn Mawr Avenue, Chicago, IL 60631

77. C. French, Gas Research Institute, 8600 West Bryn Mawr Avenue, Chicago, IL 60631

78. T. Gilles, Lennox Industries Incorporated, P.O. Box 809000, Dallas, TX $75380-9000$

79. J. C. Goldsmith, CE-332, 5H-041/FORS, U.S. Department of Energy, Washington, DC 20585

80. G. Grossman, Technion-Israel Institute of Technology, Faculty of Mechanical Engineering, Haifa 32000, Israel

81. M. E. Gunn, U.S. Department of Energy, CE-12/FORS, Washington, DC 20585

82. W. T. Hanna, Battelle Columbus Laboratories, 505 King Avenue, Columbus, OH 43201-2693 
83. J. R. Harnish, Central Environmental Systems, York International Corporation, P.O. Box 1592-191B, York, PA 17405-1592

84. F. C. Hayes, The Trane Company, 3600 Pammell Creek Road, LaCrosse, WI 54601

85. K. E. Hickman, York International Corporation, P.O. Box 1592-191A, York, PA 17405-1592

86. A. Hirsch, Midwest Research Institute, 5109 Leesburg Pike, Suite 414, Falls Church, VA 22041

87. V. Jayaraman, Consolidated Natural Gas Service Co., CNG Towers, Pittsburgh, PA 15222-3199

88. P. Joyner, Electric Power Research Institute, P.O. Box 10412, Palo Alto, CA 94303

89. T. Kapus, Building Equipment Division, CE-422, 5H-048/FORS, U.S. Department of Energy, Washington, DC 20585

90. K. Kazmer, Gas Research Institute, 8600 West Bryn Mawr Avenue, Chicago, IL 60631

91. A. Lannus, Electric Power Research Institute, P.O. Box 10412, Palo Alto, CA 94303

92. R. A. Macriss, Phillips Engineering Company, 721 Pleasant Street, St. Joseph, MI 49085

93. J. Marsala, Gas Research Institute, 8600 West Bryn Mawr Avenue, Chicago, IL 60631

94. G. Melikian, United Technology Research Center, East Hartford, CT 06108

95. M. S. Menzer, American Gas Association, 1515 Wilson Boulevard, Arlington, VA 22209

96. J. P. Millhone, CE-13, 5E-080/FORS, U.S. Department of Energy, Washington, DC 20585

97. D. E. Morrison, 333 Oxford Road, East Lansing, MI 48823

98. R. Modahl, The Trane Company, 3600 Pammel Creek Road, LaCrosse, WI 54601-7599

99. K. P. Murphy, Allied-Signal, P.O. Box 1087 R, Morristown, NJ 07960 
100. G. H. Myers, Gas Research Institute, 8600 West Bryn Mawr Avenue, Chicago, IL 60631

101. R. Nader, P.O. Box 19367, Washington, DC 20036

102. T. Occhionero, American Gas Cooling Center, 1515 Wilson Blvd., Arlington, VA 22209

103. D. Pellish, CE-332, 5H-041/FORS, U.S. Department of Energy, Washington, DC 20585

104. H. Perez-Blanco, 314 Mechanical Engineering Building, Pennsylvania State University, University Park, PA 16802

105. S. Petty, Columbia Gas System Service Corporation, 1600 Dublin Road, P.O. Box 2318, Columbus, OH 43215

106. B. A. Phillips, Phillips Engineering Company, 721 Pleasant Street, St. Joseph, MI 49085

107. B. Plzak, Refrigeration Systems Division, The Trane Company, 3600 Pammel Creek Road, LaCrosse, WI 54601-7599

108. R. Radermacher, University of Maryland, Mechanical Engineering Department, College Park, MD 20742

109. J. Rasson, Lawrence Berkeley Laboratory, 1 Cyclotron Road, Berkeley, CA 94720

110. E. A. Reid, Columbia Gas System Service Corporation, P.O. Box 2318, Columbus, $\mathrm{OH} 43215$

111. R. C. Reimann, Carrier Corporation, 6304 Carrier Parkway, P.O. Box 4800, Syracuse, NY 13221

112. G. M. Reistad, Department of Mechanical Engineering, Oregon State University, Corvallis, OR 97331

113. H. H. Rhea, Lennox Industries, Inc., P.O. Box 877, Carrollton, TX 75006

114. U. Rockenfeller, Rocky Research, 674 Wells Road, Boulder City, NV 89005

115. J. D. Ryan, CE-422, 5H-048/FORS, U.S. Department of Energy, Washington, DC 20585

116. W. A. Ryan, Gas Research Institute, 8600 West Bryn Mawr Avenue, Chicago, IL 60631 
117. P. Scheihing, CE-141, 5G-067/FORS, U.S. Department of Energy, Washington, DC 20585

118. S. V. Shelton, Thermax, Inc., 296 14th Street NW, Atlanta, GA 30318

119. H. O. Spauschus, Georgia Institute of Technology, Energy and Materials Sciences Laboratory, Atlanta, GA 30332

120. W. R. Staats, Gas Research Institute, 8600 West Bryn Mawr Avenue, Chicago, IL 60631

121. T. Statt, CE-422, 5H-048/FORS, U.S. Department of Energy, Washington, DC 20585

122. P. Swenson, Consolidated Natural Gas, CNG Tower, Pittsburgh, PA 152223199

123. D. Uselton, Lennox Industries, Inc., P.O. Box 877, Carrollton, TX 750110877

124. G. C. Vliet, Taylor Hall 116, The University of Texas, Austin, TX 78712

125. M. Wahlig, Lawrence Berkeley Laboratory, 1 Cyclotron Road, Berkeley, CA 94720

126. W. H. Wilkinson, Battelle Columbus Laboratories, 505 King Avenue, Columbus, OH 43201-2693

127. M. Williams, Department of Economics, Northern Illinois University, DeKalb, IL 60115

128. T. Zawacki, Phillips Engineering Company, 721 Pleasant Street, St. Joseph, MI 48095

129. Office of the Assistant Manager for Energy R\&D, U.S. Department of Energy, Oak Ridge Operations, Oak Ridge, TN 37831

130-139. Office of Scientific and Technical Information, Department of Energy, P.O. Box 62, Oak Ridge, TN 37831 

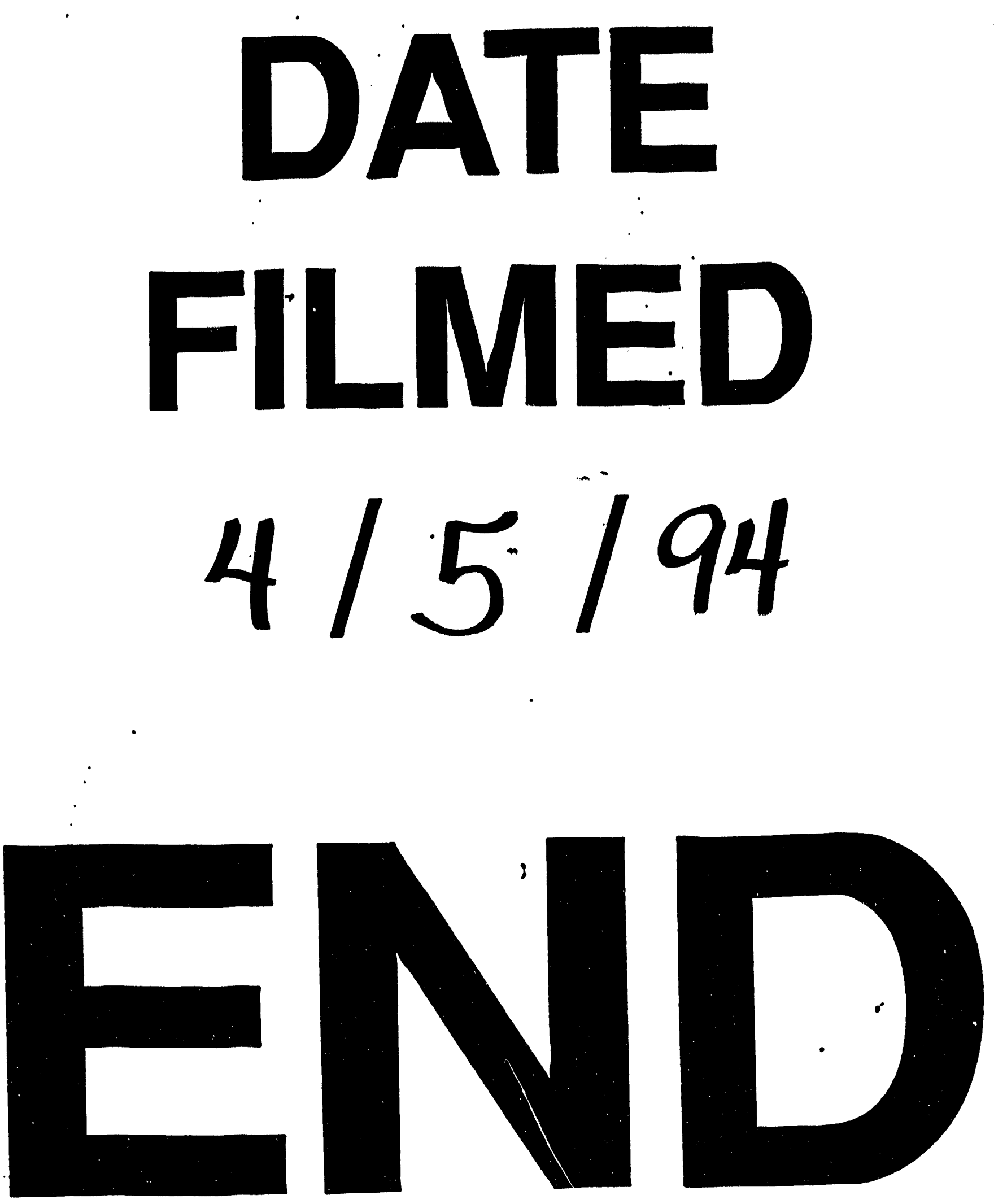
